\title{
Profiling Marketplace Change Agents (Influential) Using the Multiple Flow Communication Theory
}

\author{
Nobukhosi Dlodlo \\ Lecturer: Department of Marketing, Faculty of Management, Sciences, Vaal University of Technology \\ Private Bag X021, Vanderbiilpark, 1900 \\ Email: nobukhosid@vut.ac.za
}

\section{Doi:10.5901/mjss.2014.v5n20p705}

\section{Abstract}

This paper theoretically examines the importance of influential consumers in shaping the information retrieval and sharing practices of the general public. The principal conjectural assessment was drawn from underpinnings of the two step theory of communication and the multiple flow theory. As such, the study purports that in the world of marketing and retailing, there are three specific consumer segments that are fundamental as change agents in the propagation of marketplace related information and trends. Firstly, innovators are those consumers who have a tendency to adopt and use new products relatively early in the diffusion process. Secondly, opinion leaders are those consumers who are sought after and consulted about new products or services, by other consumers, because they are usually perceived as more knowledgeable with regard to product category related information. Thirdly, the market maven is the consumer segment consumers whose knowledge transcends many different product categories, types of distribution outlets, local marketplace developments and is also socially motivated to share this information with other consumers. This study presents both theoretical and practical implications. Theoretically, this review enriches the scholarly body knowledge on the psychology of influential consumers from the perspective of interpersonal communication dilation structures as well as innovation research. From a practical perspective, continued research on influential consumers will enable marketers to create engaging retail experiences and further gear their promotional strategies at these specific segments when launching product innovations.

Keywords: Opinion leaders, mavens, innovators, change agents, influential consumers

\section{Introduction}

Consumers' needs and demands are constantly evolving and companies are determined to satisfy them by continually creating, innovating, replacing or upgrading their cosmetic products (Brown \& Hayes, 2008). Developing revolutionary technologies and shifting customers' demands and needs contribute towards increasing the market base of specific merchandise within selected markets. As part of this initiative, companies have begun to focus on reaching the most influential consumers in the market as this could possibly mean reaching a huge part of the entire market. In order to reach these consumers, it is important to get a grip on who they are and their characteristics. This is because influential consumers are instrumental in making a new product development a success (Goldsmith, Clark \& Goldsmith, 2006). In addition, influential consumers are related to product trial (Arndt, 1967); product category involvement (Goldsmith \& Horowitz, 2006); satisfaction (Stokburger-Sauer \& Hoyer, 2009) and ultimately, loyalty to a specific product category (Feick \& Price, 1987). The concept of market influentials has been salient to scholars and practitioners, mainly because of their principal contributing role in describing patterns of adoption of innovations in the marketplace. Recent research suggests that market influentials are growing in importance primarily due to the proliferation of product choice in today's marketplace, and an associated growing need among consumers for help in dealing with more choices. Similarly, the emergence of new technology such as Web 2.0 offers the prospect of democratising communication between the influential consumers and larger numbers of fellow consumers (Geissler \& Edison, 2005).

Traditional literature examined the role of influential consumers in the field of retailing (Abratt, Nel \& Nezer, 1995) as well as the price consciousness of these change agents (Lichtenstein \& Burton, 1990). A majority of this literature referred to influential consumers as either opinion leaders (Bertrandias \& Goldsmith, 2006), innovators, or both (Arndt, 1967; Keller \& Berry, 2003). A relatively new and small group within influential consumers, market mavens (Feick \& Price, 1987), has received much less attention. That fact alone makes it interesting to take a closer look at market influential, as a whole. This study seeks to provide a theoretical underpinning on the replicated work of Feick and Price (1987) as well as Higie, Feick and Price (1987), albeit within a South African context. The concepts of mavenism and opinion leadership 
underscores that these individuals are an indispensable target market for marketing mix alterations as they spread the word about multiple product categories and new product introductions. A theoretical replication of mavenship studies within a South African context is significant because of the diversity of race and language groups within the country. In addition, the rapid social, cultural and political changes, owing to the post-apartheid era, have led to the emergence of a unique consumer segment that is thriving on the rise of a global village. Therefore, an understanding of these innovative consumers who actively try out new products earlier than others, directly express their opinions online, and share information about their knowledge of product while influencing others is a crucial issue for marketers to develop more effective strategies.

It is accepted increasingly that companies are keen to identify and engage with influencers. This is because targeting influencers is seen as a means of amplifying marketing messages, in order to counteract the growing tendency of prospective customers to ignore marketing. Therefore, it can be imagined that it would be beneficial to the company if these influential consumers would execute a proportion of all marketing efforts, but that seems like an illusion for many companies (Goodey \& East, 2008). Actually, it is not, the use of influential customers is the most cost-effective tool for commercialising new products as well as communicating important product information to many consumers. Influential consumers are consumers who spread information concerning several products and services in the marketplace (Keller \& Berry, 2003). This is an element that is inherent among some consumers with a high-affinity toward market mavenism (MM) and opinion leadership (OL). Thus, they are important consumer groups for both individuals and companies, and will constitute the underpinning for this theoretical discourse.

\section{The Value of Market Influential}

There are substantial differences in the opinions of various scholars regarding the definition of a market influencer. Keller and Berry (2003) define influencers as a range of third parties who exercise influence over the organisation and its potential customers. These scholars concede that influencers are market activists who are well connected, have active minds, affect, and are trendsetters in specific consumer markets. In addition, they have the ability to cause measurable actions and outcomes, thus the author has labeled them vital change agents. However, the medium of influence transmission (whether offline or online) also plays a considerable role in dictating the extent to which these individuals may be referred to as change agents, in this regard. Similarly, Brown and Hayes (2008) define an influencer as that peculiar individual who shapes the customer's purchasing decision, but may never be formally accountable for it. The Word of Mouth Association (WOMA, 2007) define market influentials as those people who possess greater than average reach or impact through word of mouth in a relevant marketplace. As such, defining the parameters of an influencer depends on the context, such as whether it refers to business to consumer (B2C), or business to business (B2B) information. Market influentials are specific to discrete market segments and are used as conduits for accessing the wider sphere of consumers. Gladwell (2000:14) defines these individuals as "information specialists or people that we can rely upon to connect us with new information". With their general marketplace expertise and communication skills, influential consumers are the persons that can start word-of-mouth epidemics. The new ideas that are propagated by these consumers are communicated to connectors who know a large group of people, most of them outside the community of the mavens. Connectors typically exert a lot of influence on others in their immediate environment, not because they are experts, but rather because they have relatively more social links than other people do. It should also be highlighted that the message that is transmitted by influential consumers tends to have a stickiness factor that is memorable and appealing for the masses. As such, the quality of both the messengers, as well as the content of the message, matters upon spreading the information.

Interestingly, previous researchers found that mass media channels such as the radio and newspapers are less influential than informal, personal communication (WOMMA, 2007). Based on this promulgation, explanations for the role of the influential consumer in spreading word-of-mouth were drawn from a variety of empirical studies and theoretical efforts of scholars in interpersonal communications research as well as consumer decision making studies. These theories include the two-step flow theory by Katz and Lazarsfeld (1955); the multiple flow theory (Weimann, 1982), as well as the diffusion of innovations theory (Rogers, 2003). The aforementioned theories help to present an overview of the prototypical consumer change agent, and further assist to create a grander conversation and discourse by providing relatable experiences from the ordinary consumer. These theories will be analysed in the next sections.

\subsection{The two-step flow theory of communication}

This theory asserts that information from the media moves from the sender to the receiver in two distinct stages. Firstly, 
individuals (opinion leaders) who pay close attention to the mass media and its messages receive the information. Second, these individuals are then responsible for passing on their own interpretations, in addition to the actual media content, to the ordinary consumers. As such, this theory asserts that opinion leaders limit the media influence on people's behaviour - people who initially consume media content, interpret it in light of their own values and beliefs, and then pass it on to opinion followers who have less frequent contact with media. The term personal influence was coined to refer to the process intervening between the media's direct message and the audience's ultimate reaction to that message, providing an indication of the systemic stimulus effect of the opinion leaders in distributing information (Katz, 1973), as well as in altering the attitudes and behaviour of other consumers alike (Clark \& Goldsmith, 2008).

Contrary to the magic bullet theory or the hypodermic needle theory, which argue that mass media has a powerful and direct influence on the general public, the two-step flow model stresses human agency. With the hypodermic needle theory, the message is fired directly into the audience's heads by the media (magic gun) without their notice or knowledge, causing instant reaction from the audience minds, without hesitation. The behaviour of the audience becomes passive and dormant since they cannot resist the media message. However, the two-step flow theory asserts that audiences are active elements that are predisposed and influenced by those who are part of their social group, people who are very much alike and can be trusted. The theory calls for social influence, and this is when others affect the opinions, thoughts, and behaviour of persons. Therefore, in regards to the theory, when the opinion leaders influence the decisions and thoughts of opinion followers, it may be assumed that social influence has occurred. The opinion leaders of this group are the first to try out new cultural objects, and consequently, have the most knowledge and experience with these items. Their potential approval of new products can lead to the adoption by the mass market (Katz \& Lazarsfeld, 1955; Rogers, 2003). For example, a certain individual who spends a lot of time on reading music magazines or listening to the radio makes him or her an expert on this topic. Within his or her social group of friends, this person acts as an opinion leader or mediator, and exercises some influence on what music to value and listen to. Similarly, proponents of the two-step flow theory argue that it was one of the first mass communication theories to recognise the social relations of audiences. While the hypodermic needle approach suggests the mass is composed of isolated individuals, the two-step flow theory views individuals as social beings who communicate among themselves (Katz \& Lazarsfeld, 1955). Figure 1 illustrates these two opposing theories.

Figure 1: Hypodermic model vs Two-step flow model

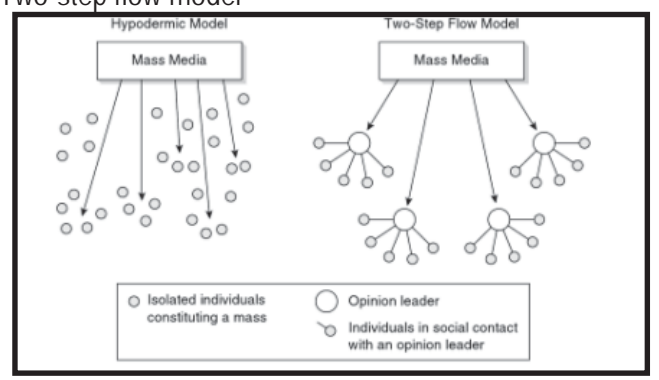

Source: (McQuail \& Windahl, 1983)

According to Katz and Lazarsfeld (1955), mass media information is channeled to the masses through opinion leadership. The people with most access to media, and having a more literate understanding of media content, explain and diffuse the content to others. Opinion leaders tend to be similar to those they influence based on personality, interests, demographics, or socio-economic factors. These leaders tend to influence others to change their attitudes and behaviour. Therefore, the two-step flow theory has improved general understanding of how mass media influences consumers' decision making at an individual level. This has provided predictive validity regarding the behaviour of various audiences; thus, providing reasons for the failure of some media campaigns in altering audience attitudes and behaviour.

Although Lazarsfeld (1948) pursued an inductive approach to theory construction (strongly grounded in empirical investigation), subsequent research critics established that application of the two-step flow theory posed a series of challenges in various contexts. The initial loophole was the assumption that mass media sources were merely restricted to opinion leaders. Second, the simplicity of one-directional communication from opinion leaders to the masses has been widely critiqued in the literature (Robinson, 1976; Weimann, 1982). Furthermore, there has been substantial evidence from researchers that initial mass media information flows directly to people on the whole, and is not relayed by opinion leaders only (Dawar, Parker \& Price, 1996; McQuail \&. \& Windahl, 1983). It appears, therefore, that this theory does not 
adequately describe the flow of learning, as it fails to acknowledge that followers also receive information from, and are influenced by, mass media. Later, researchers deciphered that information dissemination and personal influence often turn out to be two-way processes in which both opinion leaders and opinion seekers interact and exchange information with each other (Weimann, 1982; Myers and Robertson, 1972). This paved the way for the multi-step flow theory of mass communication and the diffusion of innovation theory.

\subsection{The multi-step flow model}

The multi-step flow model takes account of the complex and multi-directional relays in the word of mouth (WOM) communication process (Robinson, 1976). It observes that the influence from the media can be multi-directional and it is not necessarily downwards but can be upwards or even backwards to the media as well. This model also includes gatekeepers, who control which information will pass along to opinion leaders and opinion seekers and which will not (Weimann, 1982). Distinct from the opinion leaders, the gatekeeper does not exert influence and is not influenced by others either. In the multi-step flow model, information from the mass media can flow directly to and through different types of consumers, including opinion leaders, gatekeepers and opinion seekers. They are all part of a multi-step communication pattern. The theory presupposes that audiences are active because they send feedback to the media suggesting, appreciating or criticising things or events. There is peer-to-peer discussion as well, where the audiences with similar opinions share insights with each other. Furthermore, the dimension of opinion seeking is equally essential as the opinion leadership process (Flynn, Goldsmith \& Eastman, 1996). Without opinion seekers, there would be no opinion leaders, and vice versa. Opinion leaders could also become opinion seekers themselves because they frequently want to acquire information about new offerings in the product category of their interest.

\subsection{Diffusion of innovations theory}

Rogers (1995) studied how innovation occur, arguing that innovation consists of four stages, which are invention, diffusion (communication through social system), time and consequences. Diffusion is the process by which an innovation is communicated through certain channels over a period of time among the members of a social system, whereas an innovation is an idea, product or practice that is perceived to be new by an individual (Schiffman \& Kanuk, 2010). Communication is the process in which participants create and share information with one another to reach a mutual understanding. According to the theory, the diffusion of innovations starts with the innovators who are the first to learn about and adopt the new product or service (Rogers, 2003). The opinions of these innovators will reach the early adopters, who also accept and buy the new product or service at an early stage. In this model, innovators and early adopters serve as the opinion leaders or market mavens as they accumulate information about new products and share that knowledge with other consumers. They have a considerable influence on whether the early majority and the late majority of the consumers will accept or reject the innovation. The latest stage of the diffusion of innovations involves laggards who are more skeptical and wait to evaluate how the innovation is received by the masses before they eventually buy the new product (Rogers, 2003). The diffusion of innovations model demonstrates that, while the media diffuse most new ideas, audiences heavily rely on the recommendations and opinions that (originally) come from opinion leaders or mavens to decide if they adopt the innovation. Once the innovators and early adopters have the time to test the new product, the popularity of that innovation will grow rapidly as consumers start to communicate and are influenced by their WOM more substantially. From the late majority phase, the product has already reached its peak sales and will be consumed increasingly less before it is eventually taken off the market.

\section{Defining the Market Influential}

Various conceptualisations of the influential consumer have been propounded in the literature within various contexts. However, the current study submits that the three categories that were developed by Clark and Goldsmith (2005) are vital towards providing an underpinning foundation for the present study. These are: (1) product or brand level (opinion leadership, innovativeness), (2) category level (opinion leadership, innovatism), and (3) the marketplace in general (market mavenism).

\subsection{Innovators (early adopters)}

In consumer innovativeness research, Midgely and Dowling (1978) coined the classification of consumers into innovators 
and non-innovators. As such, consumer innovativeness has been defined as the tendency for consumers to have extensive technical knowledge and willingness to understand technological innovations in the market (Saaksjarvi, 2003). Other scholars have also referred to this consumer segment as the cohort with a high degree of innovativeness compared to other adopter categories (Rogers, 1995). Unlike market mavens, these consumers are users and purchasers of product innovations. In other words, they tend to adopt new products relatively early in the diffusion process (Clark \& Goldsmith, 2005). Simplified, this means that innovators adopt innovations quickly compared to other members of the social system (Rogers, 2003). Thus, it can be concluded that innovators want to be the frontrunners with new products and innovations, and in so doing, they might indirectly influence the purchase decisions of other consumers, although this may not be their primary goal. Since cosmetic companies release new cosmetic products on a regular basis, innovative consumers are actively seeking out those new cosmetics, while directly expressing their opinions about the product through word of mouth or the Internet, thus persuading others to follow suit. Consequently, they promote the diffusion of new products. Therefore, their existence and role are as important as those are of the media and celebrities.

The first of the reference groups, consumer innovators are a distinctive group who comprise the first 10 percent of the adopter curve (Rogers, 1995). They tend to be associated with a bell shape type of normal distribution, which is characterised as product or category specific, as opposed to being interested in all product categories across the board (Midgley \& Dowling, 1978; Rogers, 1995). It has been established in previous studies that early adopters tend to be better educated, younger and upwardly mobile (Schiffman, Kanuk \& Wisenblit, 2010). Similarly, innovators usually belong to the higher socioeconomic status relative to others in the social system. As such, these consumers can afford to take purchase risks and have the money to afford that too (Blackwell, Miniard \& Engel, 2005). In addition, numerous studies have shown that some innovators are heavy users of commercial, professional and interpersonal information sources (Goldsmith, Flynn \& Goldsmith, 2003; Fisher \& Price, 1992).

\subsection{Opinion leaders (innovatism)}

Like early adopters, opinion leaders are an attractive target for marketers as they have been shown to be effective facilitators for spreading information specific to a product or service (Chan \& Misra, 1990; Clark \& Goldsmith, 2005; Feick \& Price 1987; Goldsmith et al., 2003). They are a key group for marketers to target in that they are vital for the diffusion of product information (Rogers, 1995), but in addition, they are important actors in market economies. Opinion leaders gather, use and disseminate product and marketplace information, encouraging price competition, promoting quality and reducing the likelihood of monopoly power (Bertrandias \& Goldsmith, 2006). Price et al. (1987) argued that the diffusion of information by influential others directly affects the choices of the less informed consumers.

Opinion leadership has been defined as, "the tendency to influence purchase decisions of opinion seekers" (Stokburger-Sauer \& Hoyer, 2009). Flynn et al. (1996) state that it is not just about the purchase decision itself, but about the entire buying process. This means that opinion leaders are capable of influencing other consumers not just at the moment of the purchase decision, but earlier in the consumer buying process. Thus, opinion leaders' primary goal is to deliberately influence other consumers (and their purchase behavior), which sets them apart from innovators. Opinion seekers illustratively do not want to be unique (Bertrandias \& Goldsmith, 2006), pay high value to their social consent (Bertrandias \& Goldsmith, 2006), and are inversely related to innovativeness, which means that opinion leaders are highly innovative but their innovativeness influences opinion seekers as well (Girardi, Soutar \& Ward, 2005). Ruvio \& Shoham (2007) significantly grounded the existence of these differences between opinion leaders and opinion seekers. Thus, it can be suggested that opinion leaders want to influence opinion seekers, and opinion seekers want to be influenced by opinion leaders.

Opinion leaders' characteristics relate to levels of sociability, such as gregariousness (extraversion); outer-directed personality traits; high degree of innovativeness; positive attitudes to change; and demographic characteristics such as youth, higher education and income (Marshall \& Gitosudarmo, 1995). As such, social skills and self-confidence have been purported to be fundamental towards the propensity of these individuals to influence opinion seekers about market place issues. Usually innovativeness is tempered by social respectability or need for trustworthiness, which are not always present in the early adopters/innovators. However, opinion leaders, like early adopters, are high information seekers (Clark and Goldsmith, 2005) and use large amounts of commercial, professional and interpersonal sources of information regarding a specific product or category of interest. Opinion leaders regularly share their knowledge with other people. A few studies have shown that opinion leaders may be sought after and consulted about new products or services by other consumers because they are usually perceived as more knowledgeable with regard to high involvement purchases (Chan \& Misra, 1990). 
Rogers (1983) and Summers (1970) state that opinion leaders are technically capable regarding the use of new high-tech products as well such as tablets and smartphones. Another trait of opinion leaders is their need to feel and act differently than other consumers. They exhibit a kind of public individualism (Chan \& Misra, 1990) and high need for uniqueness. Finally, cultural dimensions do not affect opinion leaders, indicating that these individuals are not bound to a certain culture (Dawar et al., 1996). However, opinion leaders, like early adopters, are high information seekers (Clark and Goldsmith, 2005) and use large amounts of commercial, professional and interpersonal sources of information regarding a specific product or category of interest. Opinion leaders regularly share their knowledge with other people. A few studies have shown that opinion leaders may be sought after and consulted about new products or services by other consumers, because they are usually perceived as more knowledgeable with regard to high involvement purchases (Goldsmith et al., 2006).

\subsection{Market Mavens}

Feick and Price (1987) have credited the conceptualisation of the market maven as a reference group to the study based on both their general marketplace expertise and their active diffusion characteristics. Feick and Price (1987:85) define market mavens as, "individuals who have information about many kinds of products, places to shop and other facets of marketing and initiate discussions with consumers and respond to requests from consumers for marketplace information". Although market mavens have similar demographic characteristics as opinion leaders and early adopters/innovators, they differ from the opinion leaders and early adopters/purchasers on the higher levels of general knowledge about the marketplace and product marketing mix (product, prices, distribution, promotions) characteristics. Mavens have been shown to have a broader array of information about different types of products, including durable, non-durable, services and store types (Feick and Price, 1987). These consumers have also been shown to be more accurate in their evaluation of service quality than early adopters and opinion leaders (Engelland, Hopkins \& Larson, 2001). This trait makes mavens an attractive target market and change agent for retailers and other large industries that produce and/or sell a wide range of durable and fast moving consumer goods (FMCG). This contrasts sharply with the opinion leaders and early adopters who are more knowledgeable and want to share information about a specific range of products within a product category, or specific market environment characteristics.

Market mavens collect and retain information about a wider range of issues such as product quality, prices, sales, availability, store personnel characteristics and other features that may be relevant to themselves and to other consumers. The media habits of market mavens differ from those of early adopters and opinion leaders (Schneider \& Rodgers, 1993). Market mavens are more likely to read retail magazines, direct mail advertisements, and discuss retail store image attributes more freely than non-mavens (Brancaleone \& Gountas, 2007) and to be heavy users of coupons, grocery lists and budgeting tactics (Chelminski \& Coulter, 2007). Market mavens are 'smart shoppers'. They demonstrate very high levels of value consciousness by utilising coupons, grocery lists, advanced budgeting tactics, together with planning their purchases using advertising (Chelminski \& Coulter, 2007). In addition, they are heavy coupon users and are very active in providing coupons to others. Relatedly, market mavens are thought to be an important segment of consumers owing to the disproportionate influence they have on other consumers via WOM (Wangenheim, 2005), viral marketing (Goldsmith et al., 2003) and coupon distribution (Goodey \& East, 2008). These consumers are a vital promotional agent for small businesses relying on WOM, rather than large advertising budgets.

Consumers who are labelled market mavens have a great deal of influence in the marketplace, and are looked to by other consumers as credible sources of knowledge and experience (Feick \& Price, 1987; Engelland et al., 2001; Goldsmith et al., 2003). Their credibility is usually based on their altruistic motives for spreading market-related information, which includes being socially motivated (Gladwell, 2000), having expertise (Walsh, Gwinner, \& Swanson, 2004), as well as shopping for enjoyment (Clark \& Goldsmith, 2005). Yet, social capital has been argued to be the most important attribute of a market maven that gives rise to his or her influence amongst other individuals who seek advice (Buttle, 1998). Primarily it may be presupposed that market mavens may be responding to obligations to be knowledgeable about products and other shopping-relevant information in view of being labelled good shoppers (Ruvio \& Shoham, 2008). Nevertheless, their general marketplace expertise usually lends them to earlier awareness of new products, and they may be anticipating that such knowledge will serve to facilitate social exchanges and conversations. On the other hand, these consumers enjoy shopping and they demonstrate this by initiating discussions about shopping and responding to requests for shopping information from other consumers (Feick \& Price, 1987). As such, they exhibit altruistic tendencies as they have a high sense of obligation to share information with other consumers. This sharing of information results from a desire to assist other consumers, and therefore, gives market mavens a pleasurable feeling (Walsh, Gwinner \& Swanson, 2004). 
Although demographically similar to opinion leaders and early adopters, market mavens are more likely to be female, marginally lower educated than non-mavens, and more likely to come from certain sub-cultural groups (Higie et al., 1987). However, the studies of a South African consumer sample by Abratt et al. (1995), as well as an American consumer sample by Belch, Krentler and Willis-Furry (2005) have profiled the male consumer as the most likely candidate for market mavenship. On the other hand, seminal work by Geissler and Edison (2005), and Barnes and Pressey (2012) have suggested that there are no statistically significant differences between males and females regarding their affinity for mavenship behaviour leading to inconclusive results regarding the gender profiling of mavens across different contexts. Teen mavens were identified as influencers of American family decision making (Belch et al., 2005).

Table 1 shows a diagrammatic representation of the trait comparison of these three consumer segments as presented by Wiedmann, Walsh and Mitchell (2001:198).

\begin{tabular}{|l|c|l|l|}
\hline Trait & $\begin{array}{c}\text { Early adopters/ } \\
\text { innovators }\end{array}$ & Opinion leaders & Market mavens \\
\hline Purchase of a product & Yes & Not necessarily but generally yes & Not necessarily \\
\hline Usage of a product & Yes & Not necessarily & Not necessarily \\
\hline Product knowledge & Product specific & Product specific & $\begin{array}{l}\text { Specific but mainly general and } \\
\text { spanning multiple product categories }\end{array}$ \\
\hline General market knowledge (on retailers, prices, specials & No & No & Yes \\
\hline Communication style & Mainly active & Active/passive & Mainly active \\
\hline Product life cycle (PLC) stage of interest & Introduction & Primarily introduction & All stages of the PLC \\
\hline
\end{tabular}

Source: Wiedmann et al. (2001:198)

\section{Conclusions and Relevance of the Study}

This study makes the existing literature more profound by enriching the understanding of influential consumers and further challenges an extensive and inductive approach examining the salience of this consumer cohort within the context of a developing country. Important implications for marketing theory and marketing practice can be derived. Theoretically, these findings enrich the knowledge of the psychology of influential consumers from the perspective of innovative research. This provides the impetus for additional research aimed at further delineating the relationship shared among innovators, opinion leaders and market mavens as potent marketing constructs. From a practical perspective, continued research on influential consumers will enable marketers to create engaging retail experiences (XXXXX) and further gear their marketing promotional strategies at these consumer groups when launching product innovations. Therefore, individuals with a tendency toward mavenship and opinion leadership, for instance, could be integrated as powerful sources in the context of co-producing products and services. Managers and strategists are therefore compelled to identify the individuals that have influence over potential buyers, and thus, orient their marketing activities around these influencers. Influencers may be potential buyers themselves, or they may be third parties. These third parties exist either in the supply chain (retailers, manufacturers, etcetera) or may be so-called value-added influencers (such as journalists, academics, industry analysts, and professional advisers). Continued research on influential consumers will enable marketers to create engaging retail experiences and further gear their promotional strategies at these specific segments when launching product innovations.

\section{References}

Arndt, J. (1967). Role of product-related conversations in the diffusion of a new product. Journal of Marketing Research, 4(1), $291-295$.

Blackwell, R. D., Miniard, P. W. \& Engel, J. F. (2005). Consumer Behavior (10 th edition ed.). Mason, USA: Thomson South-Western.

Abratt, R., Nel, D. \& Nezer, C. (1995). Role of the market maven in retailing: A general marketplace influencer. Journal of Business and Psychology, 10(1), 31-55.

Barnes, S. J. \& Pressey, A. D. (2012). In Search of the "Meta-Maven": An Examination of Market Maven Behavior across Real-Life, Web, and Virtual World Marketing Channels. Journal of Psychology and Marketing, 29(3), 167-185.

Belch, M. A., Krentler, K. A., \& Willis-Flurry, L. A. (2005). Teen internet mavens: Influence in family decision making. Journal of Business Research, 58(5), 569-575.

Bertrandias, L. \& Goldsmith, R. E. (2006). Some psychological motivations for fashion opinion leadership and fashion opinion seeking. Journal of Fashion Marketing and Management, 10(1), 25-40.

Brancaleone, V. \& Gountas, J. (2007). Personality characteristics of market mavens. Advances in Consumer Research, 34(1), 522-527.

Brown, D. \& Hayes, N. (2008). Influencer Marketing: Who really influences your customers? New Jersey: Butterworth-Heinemann.

Clark R. A. \& Goldsmith, R. E. (2005). Market Mavens: Psychological Influences, Psychology \& Marketing, 22 (4), $289-312$. 
Clark, R. A., Goldsmith, R. E. \& Goldsmith, E. B. (2008). Market mavenism and consumer self-confidence. Journal of Consumer Behaviour, 7, 239-248.

Chan, K. K. \& Misra, S. (1990). Characteristics of the opinion leader: A new dimension. Journal of Advertising, 19(3), 53-60.

Chelminski, P. \& Coulter, R. A. (2007). On market mavens and consumer self-confidence: A cross-cultural study. Psychology and Marketing, 24(1), 69-91.

Dawar, N., Parker, P. M. \& Price, L. J. (1996). A cross-cultural study of interpersonal information exchange. Journal of International Business Studies, 27, 497-516.

Engelland, B. T.,Hopkins, C. D. \& Larson, D. A. (2001). Market mavenship as an influencer of service quality evaluation. Journal of Marketing Theory and Practice, 9, 15-26.

Feick, L. F. \& Price, L. L. (1987). The market maven: A diffuser of marketplace information. The Journal of Marketing, 51(1), 83-97.

Fisher, R. J. \& Price, L. L. (1992). An Investigation into the Social Context of Early Adoption Behavior. Journal of Consumer Research, 19 (December), 477-486.

Flynn, L. R., Goldsmith, R. E. \& Eastman, J. K. (1996). Opinion leaders and opinion seekers: Two new measurement scales. Journal of the Academy of Marketing Science, 24(2), 137-147.

Geissler, G.L. \& Edison, S.W. (2005). Market mavens' attitudes towards general technology: implications for marketing communications, Journal of Marketing Communications, 11, 73-94.

Girardi A, Soutar, G. N. \& Ward, S. (2005). The Validation of a Use Innovativeness Scale. European Journal of Innovation Management, $8(4), 471$.

Gladwell, M. (2000). The Tipping Point: How Little Things Can Make a Big Difference. Boston: Little, Brown.

Goldsmith, R. E. \& Horowitz, D. (2006). Measuring motivations for online opinion seeking. Journal of Interactive Advertising, 6 (2), 1-16.

Goldsmith, R. E., Clark, R. A. \& Goldsmith, E. B. (2006). Extending the psychological profile of market mavenism. Journal of Consumer Behaviour, 5(5), 411-419.

Goldsmith, R. E., Flynn, L. R., \& Goldsmith, E. B. (2003). Innovative consumers and market mavens. Journal of Marketing Theory and Practice, 11(4), 54-65.

Goodey, C. \& East, R. (2008). Testing the market maven concept. Journal of Marketing Management, 24(3), 265-282.

Higie, R.A., Feick, L.F. \& Price, L. L. (1987). Types and amount of word-of-mouth communications about retailing, Journal of Retailing, $63,260-278$.

Katz, E., \& Lazarsfeld, P. (1955). Personal Influence, New York: The Free Press.

Katz, E. (1973). The two-step flow of communication: an up-to-date report of an hypothesis. In Enis and Cox(eds.),Marketing Classics, p175-193.

Keller, E \& Berry, J. (2003). The Influentials. New York: Free Press.

Lichtenstein, D. R. \& Burton, S. (1990). An assessment of the moderating effects of market mavenism and value consciousness on price-quality perception accuracy. Advances in consumer research, 17(1), 53-59.

Marshall, R. \& Gitosudarmo, I. (1995). Variation in the characteristics of opinion leaders across cultural borders. Journal of International Consumer Research, 8(1), 5-22.

McQuail, D. \& Windahl, S. (1983). Communication Models for the Study of Mass Communication. London: Sage.

Midgley, D. F. \& Dowling, G. R. (1978). Innovativeness: The Concept and Its Measurement. Journal of Consumer Research , 4, $229-242$.

Myers, J. H., \& Robertson T. S. (1972). Dimensions of opinion leadership. Journal of Marketing Research 9, 41-46.

Robinson, J. (1976). Interpersonal Influence in Election Campaigns: Two-Step Flow Hypothessis. Public Opinion Quarterly, 40, $304-319$.

Rogers, E. M. (1995). Diffusion of innovations (3rd ed.). New York: Free Press.

Rogers, E. M. (2003). Diffusion of innovations (5th ed.). New York: Free Press.

Ruvio, A. \& Shoham, A. (2007). Innovativeness, exploratory behavior, market mavenship, and opinion leadership: An empirical examination in the asian context. Psychology and Marketing, 24(8), 703-722.

Saaksjarvi, M. (2003). Consumer adoption of technological innovations. European Journal of Innovation Management, 6(2), 90 - 100.

Schiffman, L. G., Kanuk L. L. \& Wisenblit J. (2010). Consumer behaviour. (10th ed.), New Jersey: Pearson Prentice Hall.

Schneider, K. C. \& Rodgers, W. C. (1993). Generalized marketplace influencers' (market mavens') attitudes toward direct mail as a source of information. Journal of Direct Marketing, 7(4), 20-28.

Stokburger-Sauer, N. E. \& Hoyer, W. D. (2009). Consumer advisors revisited: What drives those with market mavenism and opinion leadership tendencies and why? Journal of Consumer Behaviour, 8(2), 100-115.

Summers, J. O. (1971). Generalised change agents and innovativeness. Journal of Marketing Research, 8(3), 11-15.

Walsh, G., Gwinner, K. P. \& Swanson, S. R. (2004). What makes mavens tick? Exploring the motives of market mavens' initiation of information diffusion. Journal of Consumer Marketing, 21(2), 109-122.

Wangenheim, F. V. (2005). Postswitching negative word of mouth. Journal of Service Research, 8(1), 67-78.

Weimann, G. (1982). On the importance of marginality. One more steps into the two step flow communication theory. American Sociological Review, 47 (1), 764-773.

Wiedmann, K. P., Walsh, G. \& Mitchell, V. W. (2001). The man maven: An agent for diffusing market information. Journal of Marketing Communications, 7(4), 195-212.

Womma (2007). Press Release: Word of Mouth Marketing Is Here to Stay: WOMMA Reaches Membership Milestone, Looks Forward to Industry Growth. [Online] Available: http://www.womma. org/news/008905.php (7 February 2014). 